\title{
Biophysical therapy and biostimulation in unfavorable bony circumstances: adjunctive therapies for osseointegration
}

\author{
Yong-Deok Kim \\ Department of Oral and Maxillofacial Surgery, School of Dentistry, Pusan National University, Yangsan, Korea
}

\begin{abstract}
J Korean Assoc Oral Maxillofac Surg 2012;38:195-203)
Dental implants using titanium have greatly advanced through the improvement of designs and surface treatments. Nonetheless, the anatomical limits and physiological changes of the patient are still regarded as obstacles in increasing the success rate of implants further, even with the enhancement of implant products. So there have been many efforts to overcome these limits. The intrinsic potential for bone regeneration can be stimulated through adjuvant treatments with the continuous improvement of implant properties, and this can play an important role in achieving optimum osseointegration toward peripheral bone tissue and securing ultimate long-term implant stability in standard surgical procedures. For this purpose, various chemical, biological, or biophysical measures were developed such as bone grafts, materials, pharmacological agents, growth factors, and bone formation proteins. The biophysical stimulation of bone union includes non-invasive and safe methods. In the beginning, it was developed as a method to enhance the healing of fractures, but later evolved into Pulsed Electromagnetic Field, Low-Intensity Pulsed Ultrasound, and Low-Level Laser Therapy. Their beneficial effects were confirmed in many studies. This study sought to examine bone-implant union and its latest trend as well as the biophysical stimulation method to enhance the union. In particular, this study suggested the enhancement of the function of cells and tissues under a disadvantageous bone metabolism environment through such adjunctive stimulation. This study is expected to serve as a treatment guideline for implant-bone union under unfavorable circumstances caused by systemic diseases hampering bone metabolism or the host environment.
\end{abstract}

Key words: Lasers, Ultrasonic therapy, Osteoblasts, Biosynthesis, Dental implants

[paper submitted 2012. 4. 3 / revised 1st 2012. 4. 4, 2nd 2012. 5. 14 / accepted 2012. 5. 16]

\section{Introduction}

The success of the dental titanium implant is influenced by the surgeon's skill, quality and quantity of bone, and oral hygiene of the patient. The overall success rate is has been reported about $95 \%$. Implant success as manifested by the osseointegration between implant and bone not only secures the stability and retention of the implant but also guarantees long-term success. On the other hand, a dental implant fails when the implant and the bone are not precisely integrated and sometimes due to infection, smoking, breakage of the

\section{Yong-Deok Kim \\ Department of Oral and Maxillofacial Surgery, Pusan National University Dental Hospital, 20, Geumo-ro, Mulgeum-eup, Yangsan 626-787, Korea TEL: +82-55-360-5100 FAX: +82-55-360-5104 \\ E-mail:ydkimdds@pusan.ac.kr}

(c) This is an open-access article distributed under the terms of the Creative Commons Attribution Non-Commercial License (http://creativecommons.org/licenses/by-nc/3.0/), which permits unrestricted non-commercial use, distribution, and reproduction in any medium, provided the original work is properly cited. implant itself, or breakage of the implant component.

To minimize such failures, the surgeon performs bone grafting in various ways to supplement insufficient bone mass or quality, increase the efficiency of bone union by improving the design or shape of the implant itself, or improve the immunity of the host with ancillary drug therapy for deteriorated bone metabolism or supplement insufficient metabolic capacity.

The properties of dental implant using titanium have been enhanced considerably through the improvement of design and surface treatment. Nonetheless, the anatomical limits and physiological changes of the host-the patient-are still regarded as obstacles in increasing success implantation further even with the enhancement of implant products, and there were many efforts to overcome them. For this, efforts to enhance the metabolic capacity of the bone tissue are required along with various surgical principles and prosthetic rules; such efforts can be established as the acceptable clinical technique that is ancillary but non-invasive and

*A lecture on this research was delivered at the 53rd Symposium on IV. IMPLANT held by the Korean Association of Oral and Maxillofacial Surgeons in 2012. This research was supported by the Basic Science Research Program through the National Research Foundation of Korea (NRF) funded by the Ministry of Education, Science, and Technology (2011-0026921). 
applied economically when difficulty or failure of bone union is expected.

The intrinsic potential for bone regeneration can be stimulated through adjunctive treatment along with the continuous enhancement of implant properties, and this can play an important role in standard surgical procedure in terms of achieving optimum bone union toward peripheral bone tissue and securing the ultimate long-term implant stability. For this, a variety of chemical, biological, or biophysical measures were developed such as bone graft material, pharmacological agent, growth factor, and bone formation protein. The biophysical stimulation of bone union includes non-invasive and safe methods. In the beginning, it was developed as a method to enhance the healing of fracture, but later evolved into pulsed electromagnetic field (PEMF), low-intensity pulsed ultrasound (LIPUS), and low-level laser therapy (LLLT); their beneficial effects were confirmed in many studies.(Fig. 1) This study sought to examine boneimplant union and its latest trend as well as the biophysical stimulation method to enhance the union. In particular, this study suggested the enhancement of the function of cells and tissues under unfavorable bone metabolism environment through such adjunctive stimulation.

\section{PEMF, LIPUS, and LLLT}

\section{PEMF}

Various techniques were applied to enhance bone healing such as biophysical stimulation to prevent problems due to insufficient bone healing in the region with bone defect. Among them, PEMF has been used as non-invasive anabolic method for over 30 years for the healing of bone fracture, osteotomy, osteoarthritis, and osteoporosis in the domain of orthopedics ${ }^{2,3}$. PEMF influences DNA synthesis in the osteoblast to stimulate bone formation, and this increases cellular differentiation and proliferation ${ }^{4,5}$. Likewise, PEMF reportedly enhances bone marker gene expression and stimulates bone matrix formation, calcification, and transforming growth factor (TGF)- $\beta 1^{6,7}$. Chang et al. ${ }^{8}$ reported that the application of PEMF increased the manifestation of alkaline phosphatase in the beginning of osteogenesis. A number of later animal and human body studies showed PEMF effects in various clinical situations intended to increase bone regeneration.

In 1992, Greenough ${ }^{9}$ observed that PEMF mainly influenced vascular growth as well as the healing of tissue. Roland et al. ${ }^{10}$ confirmed PEMF's influence on vascular formation within the cell and suggested PEMF as a means of enhancing the quality of re-vascularized tissue. Smith et al. ${ }^{11}$ observed that the topical application of PEMF in wavelength form caused the expansion of fine arteries in mice muscles.

In human studies, PEMF treatment was applied as additional treatment for the delayed healing of foot and ankle joint and to stimulate bone regeneration in patients with non-union fracture $^{12,13}$. The success rate was low, however. Furthermore, using PEMF as an ancillary measure increased the success rate of radiological spine fusion and accelerated the regeneration process ${ }^{14,15}$. It was successfully applied as well to non-union on anterior cervical fusion ${ }^{16}$.

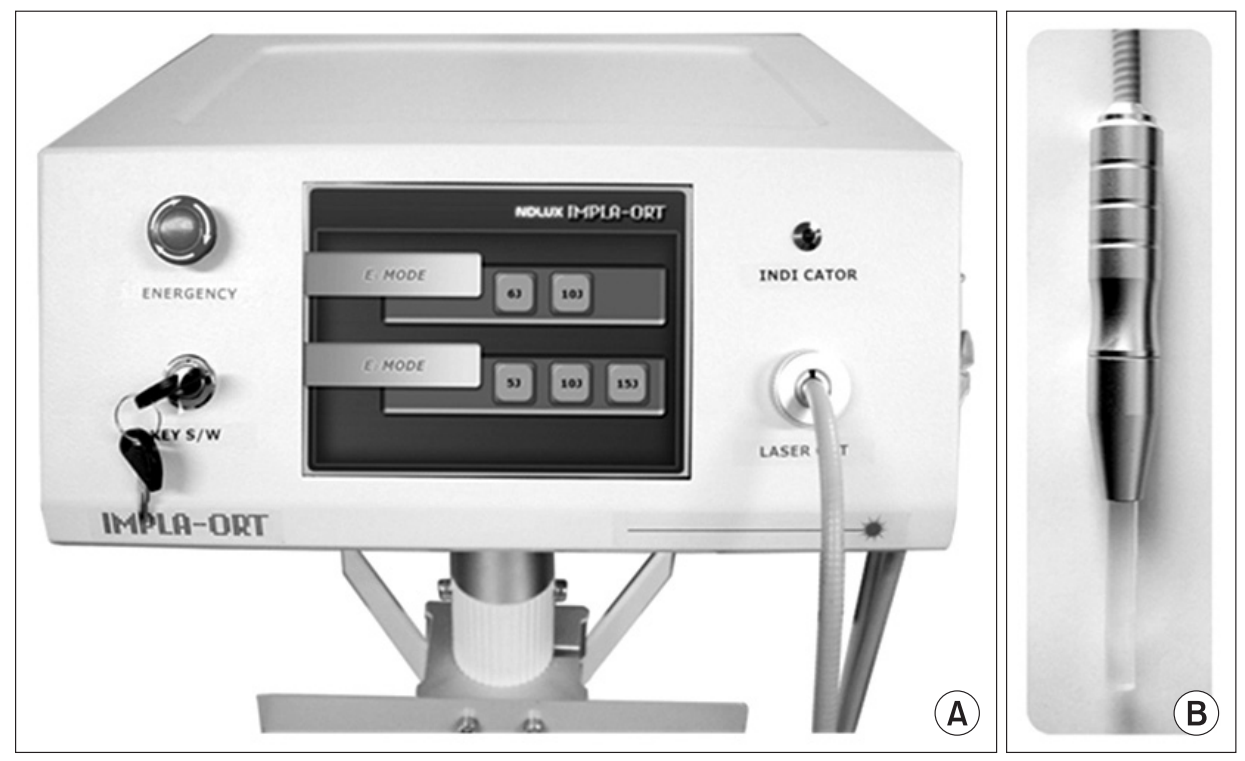

Fig. 1. A. Low-level laser machine. B. Intraoral probe ${ }^{62}$.

Yong-Deok Kim: Biophysical therapy and biostimulation in unfavorable bony circumstances: adjunctive therapies for osseointegration. J Korean Assoc Oral Maxillofac Surg 2012 
The mechanism in the molecular level of PEMF stimulation has not been clarified, but PEMF was confirmed to change clearly the function of adenosine A2A receptor in intensity, time, and temperature-dependent manner within the living body and suppress the generation of superoxide anion eventually. This can control inflammatory reaction, but the role of the mechanism in case of osseointegration and loosening due to bacterial infection should be clarified through further studies ${ }^{17}$. In vivo study, PEMF stimulation on the osteoprogenitor cell and osteoblast resulted in the increase of division and multiplication of the growth factor or division factor including extracellular trait, TGF- $\beta 1$, bone morphogenetic protein (BMP)-2, and BMP- $4^{4,18}$. These studies showed that the positive effect of PEMF mainly influenced vascular growth and discharged vascularizing factors such as interleukin (IL)-8, b-fibroblast growth factor (b-FGF), and vascular endothelial growth factor (VEGF) with regard to bone growth ${ }^{19}$. In recent studies, Chang et al. ${ }^{20}$ reported that PEMF accelerated the apoptosis of osteoclast originating with the cultivation of primary osteoblast and myoblast. They also suggested the application of PEMF to bone diseases related to osteoclast such as osteoporosis. Furthermore, clear increase and decrease in bone generation and resorption, respectively, were observed when the bone marrow culture in mice was exposed to different degrees of PEMF. This suggests the possibility of controlling the density of osteoclastogenesis, bone resorption, osteoprotegerin, receptor activator of nuclear factor kappa-B ligand, and macrophage colony-stimulating factor in the bone marrow culture system with different degrees of $\mathrm{PEMF}^{21}$.

There are a few animal studies on the impact of PEMF on bone-implant fusion. Shimzu et al. ${ }^{22}$ placed implants on the tibia of rabbits and noted the acceleration of bone formation or maturation while studying the impact of PEMF on bone growth toward porous hydroxyapatite and porous tricalcium phosphate. This proves the potential for the clinical application of PEMF for aseptic loosened implant treatment in orthopedics.

Spadaro et al..$^{23}$ placed stainless steel implants on the bone marrow cavity of rabbits to conduct a test on an implant with mobility and observed that PEMF accelerated osteogenesis around the implant; this effect appeared more clearly in the tibia than the femur. This implies that PEMF can be clinically applied to the fixture with aseptic mobility in the domain of orthopedics.

In other animal tests, Ijiri et al. ${ }^{24}$ studied the effect of PEMF on bone growth with porous-coated implant. The implant was placed on the humerus of a Japanese white rabbit and the titanium implant covered with bead having diameter of 250300 microns, and researchers observed a clear increase of bone growth toward porous-coated implant in animals treated with PEMF compared with the control group. Increased bone contact ratio and bone area ratio of rough-surface implant were also observed after placing the implant on the femur of a Japanese white rabbit. The degree of development varied according to volume and exposure time ${ }^{25}$.

PEMF stimulation was applied to patients to reinforce implant-bone fusion. Specifically, it was applied to hip prosthesis. In 1995, Steinberg reported the case of a 44-yearold patient who exhibited change in bone resorption around the distal femoral prosthesis treated with anti-inflammatory drugs and $\mathrm{PEMF}^{26}$.

Konrad et al. ${ }^{27}$ applied PEMF treatment to 24 patients with prosthesis for loosened hip and observed patients 6 months and 1 year after the treatment ended. Pain and flexing and extending hip movement were noticeably enhanced. Radiological findings did not change significantly, but $\mathrm{Tc}^{99 \mathrm{~m}}$ scintigraphy and ultrasonography showed improvements; this effect lasted for 1 year. Note, however, those patients with seriously loosened hip or who had pain during resting did not respond to PEMF treatment. For this, the researchers concluded that PEMF treatment was effective, but not for patients with serious symptoms.

Kennedy et al. ${ }^{28}$ conducted a double-blind clinical trial targeting 37 patients with loosened cemented hip prostheses. After 6 months of PEMF treatment, the placebo group recorded an $11 \%$ success rate, whereas patients who did not receive PEMF treatment posted a 53\% success rate. Note, however, that researchers observed a $60 \%$ recurrence after 14 months, increasing up to $90 \%$ in 3 years. Based on the result, the researchers concluded that the application of PEMF for loosened cemented hip prostheses was only acceptable in delayed hip plastic surgery ${ }^{28}$.

Generally, the clinical use of PEMF is still controversial. The advantage of the biomechanical method in enhancing implant bone union must be proven along with the optimum adjustment of magnetic intensity and the most effective duration and treatment period.

\section{LIPUS}

LIPUS is a type of mechanical energy transmitted through living tissue such as the water pressure wave, which is higher than the level of sound that can be detected by the human 
ear. This is absorbed in proportion to the density of the tissue it passes through ${ }^{29}$. The fine mechanical properties formed in the living tissue are believed to be able to manifest the biophysical phenomenon that can stimulate fracture healing.

The in vitro study showed that the application of LIPUS to osteoblast, fibroblast, and monoblast induced cell cultivation, division, and osteogenic vascularization. Assimilative and vascularizing factors such as TGF- $\beta 1$, b-FGF, IL-8, prostaglandin E2, and VEGF were increased, whereas pre-inflammatory cytokine such as IL-6 and tumor necrosis factor-alpha decreased ${ }^{20,30}$. In recent studies, LIPUS stimulation directly influenced osteogenic cells to intensify the formation of mineral crystals and cartilage generation of mesenchymal stem cell derived from the marrow ${ }^{31,32}$.

High-intensity ultrasound was used to stimulate osteogenesis in early animal tests. Nonetheless, this resulted in inconsistent results for osteogenesis. At higher intensity, researchers reported reduced callus formation, delayed bone healing, necrosis, and concentrated fiber tissue formation; at lower intensity, however, increased callus formation and faster odontoclasis healing were noted ${ }^{29}$. These contrasting results accelerated additional studies, eventually leading to the use and development of LIPUS for the stimulation of osteogenesis $^{33}$

LIPUS treatment was applied in various tests and studies to accelerate the recovery of the bone's mechanical characteristics such as maximum torque and torsional rigidity during recovery from fracture ${ }^{29}$. Ultrasound has been reported to accelerate fracture healing when applied during the inflammatory period of bone generation and initial proliferative period $^{34}$. Many intracellular studies suggest that LIPUS does not influence the remodeling stage of fracture healing but affects initial inflammation or during callus formation in the curing process, mainly during the vascularization period, and during the period of ossification inside cartilage ${ }^{35,36}$. Animal studies showed the positive effect of LIPUS treatment in the mature stage in bone regeneration during distraction osteogenesis, with the observation showing clearly more callus formations, higher inorganic material density, and higher solidity for bone regeneration ${ }^{37,38}$. The effect of LIPUS was manifested more clearly when applied during the distraction period than the maturation period in the overall process and was mediated through the endochondral pathway $^{39}$. In animal studies, LIPUS accelerated bone regeneration under fast distraction in a volume-dependent manner ${ }^{40}$.

Many studies show the different roles and impacts of
LIPUS according to the intensity and frequency of ultrasound, and there are no agreements as to the specific intensity and frequency ${ }^{41}$.

A number of clinical studies were conducted on the effect of LIPUS in relation to the acceleration of fracture healing and treatment of non-union in human patients ${ }^{42}$. Heckman et al. ${ }^{43}$ observed that it took less time to achieve clinical and radiological union as additional treatment for non-vascular or grade 1 open tibial shaft fracture healing.

The mechanism of ultrasound in accelerating bone generation is not yet clear and is being studied, and other mechanisms are being suggested. Ultrasound has been hypothesized to be possibly able to cause change in cells and tissues through the increase of temperature following energy absorption since a slight change of temperature can allow LIPUS to influence a few enzymes such as matrix metalloproteinase 1 (or collagenase 1$)^{44}$. Note, however, that more recent studies suggest that LIPUS can be related to non-thermal effect in cells and tissues such as acoustic streaming and cavitation that increases collagen synthesis and overall cellular activity with augmented genetic manifestation. This appears to influence the diffusion rate and membrane permeability. In addition, LIPUS produces mechanical stimulation through increased blood flow and induced micromotion ${ }^{29,41}$.

There is no clinical study on LIPUS stimulation and bone union conducted on the human body. Instead, only animal studies indicating the location of bone deposition and increased bone growth were carried out ${ }^{45-47}$.

According to Tanzer et al. ${ }^{47}$, LIPUS influences the increase of bone growth after an implant is placed on the ulna of a dog using porous intramedullary rods (tantalum). An average of $119 \%$ bone growth was observed in the implant treated with ultrasound compared to the control group. In other studies, Tanzer et al. ${ }^{46}$, reported that the group treated with LIPUS exhibited $18 \%$ increase in bone growth compared to the control group for the treatment using fully porous bicortical implants (titanium). LIPUS treatment exhibits the largest impact within the first 2-3 weeks of stimulation. These findings suggest the use of LIPUS for the bone fusion of the alternative product for non-cemented, porous-coated total joint in human patients.

As to the potential of extra-oral application of ultrasound for enhancing implant-bone union in human patients, further studies should be conducted to clarify the stimulation mechanism. Not only will a well-designed clinical study clarify this; such is also required in optimizing ultrasound parameter and establishing the protocol for clinical use. 


\section{LLLT}

Known as cold laser, soft laser, biostimulation, or photobiomodulation, LLLT is the therapeutic approach that has been highlighted recently. It basically exposes cell or tissue to laser or low-level red or near-infrared (IR) light generated from light-emitting diode. LLLT stimulates or controls cellular function to minimize the extinction of cell or tissue, accelerates the healing of fractures, fast recovery from the damage of soft tissue, nerve, bone, and cartilage, and relieves acute and chronic pain and inflammation.

The absorption and dispersion of light within the tissue are dependent on wavelength. The major chromophores of the tissue are hemoglobin and melanin, and they have strong absorption band to wavelength shorter than $600 \mathrm{~nm}$. For this, the so-called "optical window", an area that exhibits the best tissue penetration efficiency of light, is the red visual light and near-IR light wavelength. Blue, green, and yellow lights can have significant impact on optically transparent cultured cells, but low-level laser applied to animals and patients mostly include red visual light and near-IR light (600-1,070 $\mathrm{nm})$.

According to the first law of photobiology, the photon has to be absorbed into the absorption band in the chromophores or photoceptor for the low-level light to have a certain effect on a living biosystem ${ }^{48}$. The cytochrome c oxidase as the sub-unit of mitochondria electron-transport chain acts as the primary photoreceptor in mammal cells since it has absorption band of up to $1,000 \mathrm{~nm}^{49}$.

Chen et al. ${ }^{50}$ proved that laser irradiation on cultured embryonic osteoblast of mice and another type of cell in the animal test increased the synthesis of reactive oxygen species (ROS) and adenosine triphosphate (ATP) inside the cell. According to them, exposure to low-level laser in the red visual light and near-IR light area emits nitrogen oxide (NO). This means that ROS plays an important role for the signaling pathway of low-level laser. This can increase the transcription of various genetic substances by inducing the manifestation of redox-sensitive transcription factors such as nuclear factor kappa $\mathrm{B}^{50}$. The accurate wavelength and power of the light transferred to the cells during an appropriate period of time are absorbed by specific photoreceptors such as cytochrome c oxidase. This photoreceptor photodissociates inhibitory NO to increase enzyme activity and accelerates mitochondrial respiration and ATP production. Proteins such as hemoglobin and myoglobin trigger the additional discharge of NO, leading to downstream cell signaling.
Although the basic mechanism of low-level laser is not completely revealed, the results of in vitro, animal, and clinical tests show that low-level laser treatment prevents cell apoptosis and enhances cell multiplication, migration, and adhesion $^{51-53}$. Such effect on cells can serve as the basis for clinical application.

LLLT is used not only by medical doctors but also by specialists such as physical therapist ${ }^{54}$, dentist ${ }^{55}$, dermatologist, rheumatism specialist ${ }^{56}$, etc. Furthermore, laser treatment is widely applied in veterinary medicine, sports medicine, and rehabilitation clinic. Currently, preclinical studies and clinical application are carried out to treat serious and critical diseases ${ }^{57}$ such as degenerative neurological diseases including heart attack ${ }^{58}$, coronary diseases, nerve regeneration and spinal cord damage, cerebral infarction, traumatic brain injury ${ }^{59}$, Alzheimer's disease, and Parkinson's disease with LLLT.

For bone metabolism capacity in particular, stimulation by compression or function of osteoblast under a hypoxic environment was accelerated through laser irradiation; this becomes the basis ${ }^{60}$ for clinical application in disadvantageous situations such as aging and post-surgical care.

\section{Application in osseointegration and implantology}

The enhancement of bone metabolism has been challenged in the domain of dentistry as well through the various methods described above. In particular, it has been applied and studied mainly before and after implant placement, which is directly related to bone metabolism and osseointegration and bone grafting.(Table 1)

In the case of PEMF, a study showed the positive effect on osseointegration in early animal tests ${ }^{25}$; some observations showed that its use as bone growth stimulator inside the oral cavity led to the acceleration of bone growth around the dental implant ${ }^{61,62}$, and that its application to the bone around the implant triggered the acceleration of bone healing ${ }^{63,64}$. In contrast, some studies reported that PEMF hampered the division of osteoblast ${ }^{65}$. According to some reports, however, the low-magnitude, high-frequency field had a positive effect on the increase of bone mass around the implant in ovariectomized mice $^{66}$. Nonetheless, PEMF has limits in terms of the application time in all these studies; the application time is suggested in a great variety from 30 minutes to 3 hours, whereas pulse frequency and width are not standardized. In other words, a number of additional studies are required in relation to clinical applications even with a variety of 
Table 1. Summary of the main factors influencing biomaterial osseointegration positively or negatively

\begin{tabular}{|c|c|c|}
\hline Factors & Enhancement of osseointegration & Inhibition of osseointegration \\
\hline Implant-related factors & $\begin{array}{l}\text { Design } \\
\text { Chemical composition (wide or narrow porous) } \\
\text { Surface topography } \\
\text { Coatings }\end{array}$ & Inappropriate porosity \\
\hline Status of host bone bed & $\begin{array}{l}\text { Minimal surgical trauma } \\
\text { Vascularity and cellularity of implantation site }\end{array}$ & $\begin{array}{l}\text { Bone defect } \\
\text { Osteoporosis } \\
\text { Rheumatoid arthritis } \\
\text { Smoking } \\
\text { Advanced age }\end{array}$ \\
\hline Mechanical stability & $\begin{array}{l}\text { Primary implant stability } \\
\text { No micromotion }\end{array}$ & Excessive implant mobility (interface motion) \\
\hline Adjuvant therapies & $\begin{array}{l}\text { Bone grafting (autogenous or allograft) } \\
\text { Osteogenic coatings (BMPs, TGF-) } \\
\text { Biophysical stimulation (PEMFs and LIPUS) } \\
\text { Biostimulation (LLLT) } \\
\text { Systemic administration of ibandronate and human } \\
\text { parathyroid hormone 1-34 }\end{array}$ & $\begin{array}{l}\text { Irradiation } \\
\text { Pharmacological agents: } \\
\text { (cyclosporin A, methotrexate, cis-platinum, warfarin, } \\
\text { indomethacin) }\end{array}$ \\
\hline
\end{tabular}

(BMPs: bone morphogenetic proteins, TGF: transforming growth factor, PEMFs: pulsed electromagnetic fields, LIPUS: low-intensity pulsed ultrasound, LLLT: low-level laser therapy)

Yong-Deok Kim: Biophysical therapy and biostimulation in unfavorable bony circumstances: adjunctive therapies for osseointegration. J Korean Assoc Oral Maxillofac Surg 2012
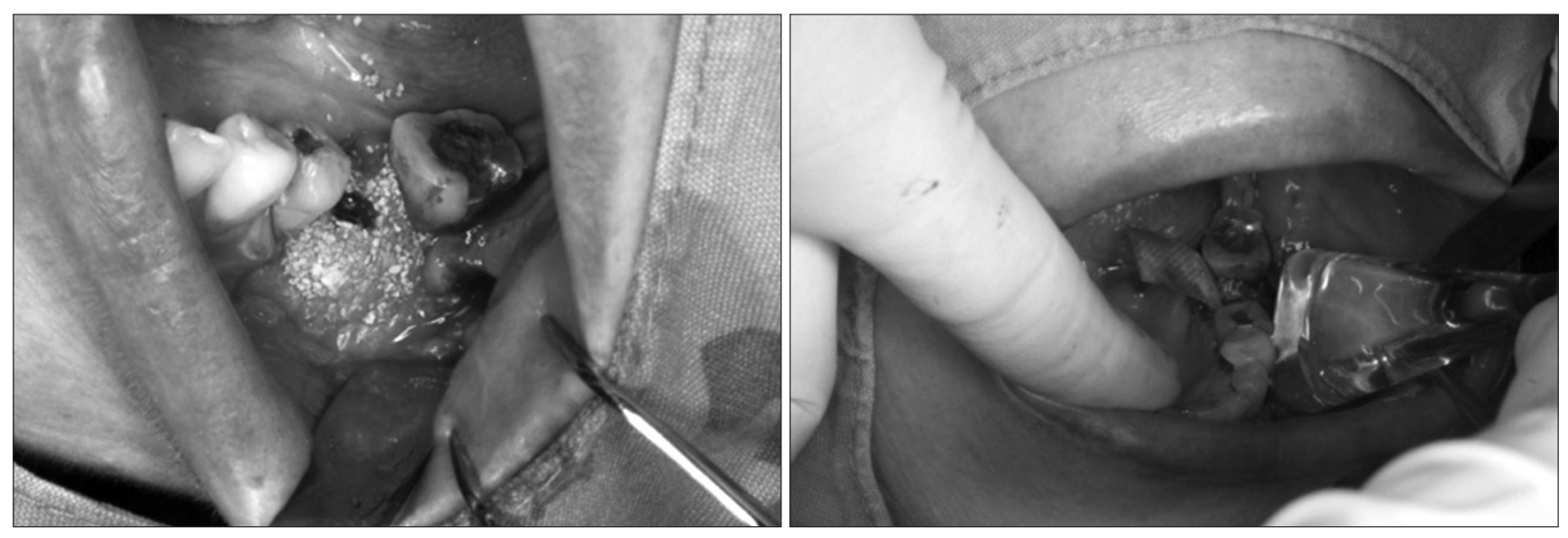

Fig. 2. The application of low-level laser therapy was chosen to stimulate bone healing during guided bone regeneration around the exposed threads of the previous implant.

Yong-Deok Kim: Biophysical therapy and biostimulation in unfavorable bony circumstances: adjunctive therapies for osseointegration. J Korean Assoc Oral Maxillofac Surg 2012

advanced research studies, and it is not efficient in actual clinical practice since the application time is too long.

There are also reports related to osseointegration in animal and clinical tests concerning LIPUS. According to a report, the group exposed for 10 minutes twice a day for 21 days manifested the acceleration of osseointegration around the dental implant compared with the control group ${ }^{67}$; another report also showed the acceleration of healing in gingival soft tissue cell due to the increase of connective tissue growth factors through mitogen-activated protein kinase signaling pathway ${ }^{68}$. Another study reported that LIPUS induced BMP2 to accelerate bone formation in animal models ${ }^{69}$. Note, however, that the inconsistent volume and the limitation of application time can be problems, and there has yet to be clear basis for clinical application.

On the other hand, a relatively large number of studies were conducted on LLLT. Recently, bone formation and stabilization around the mini-implant were enhanced with low-level laser irradiation. A report stated that this was attributed to increased BMP- $2^{70}$, and a study reported its positive effect in relation to the reaction of peripheral tissues after root canal treatment ${ }^{71}$. On the other hand, the doubleblind trial that applied LLLT after implant placement revealed good initial stability and excellent bone quality in bone-implant interface, whereas figures such as macroscopic implant stability quotient did not reflect the effect ${ }^{72}$. In addition, 
the effect of low-level laser in disadvantageous bone environment was reported in the in vitro test ${ }^{60}$. Still, LLLT also requires more additional studies for clinical application.

Nonetheless, LLLT appears to have relative excellence among the three applicable and researchable adjunctive bone metabolism enhancement methods since it takes shorter time to apply and foregoes the need for direct contact with the target, serving as advantages in actual clinical application. (Fig. 2) This is probably why LLLT is receiving more attention in recent studies.

\section{Conclusion}

Regardless of the continuous advancement of biomaterials, intrinsic bone regeneration potential can be stimulated by an adjuvant treatment for basic surgical technique to accelerate and maximize bone growth. Obtaining the maximum osseointegration toward the neighboring bone has important clinical significance, and various chemical and biophysical techniques have been tested for this purpose. Such adjuvant treatments, which increase local inner bone growth to enhance bone-implant interface, include bone grafting material, pharmacological drug, growth factor, and bone formation protein.

For biophysical stimulation in the osseointegration process, LIPUS and PEMF form two non-invasive and exogenous local applications exhibiting favorable effects in most studies. Their applications did not exhibit any systemic or local adverse effect. Observations disputing their effects point to a variety of elements. In other words, future studies need to show useful effects in the experimental studies to clarify the activation mechanism at the molecular level and determine variables adequate for the biophysical activation method. Variables to be determined include the minimum strength required for activation, most effective period of ordinary exposure, and entire treatment period. Verification for the dose and application time through more prospective clinical studies must be conducted in advance as well for LLLT.

\section{References}

1. Esposito M, Grusovin MG, Willings M, Coulthard P, Worthington HV. The effectiveness of immediate, early, and conventional loading of dental implants: a Cochrane systematic review of randomized controlled clinical trials. Int J Oral Maxillofac Implants 2007;22:893-904

2. Bassett CA, Mitchell SN, Gaston SR. Pulsing electromagnetic field treatment in ununited fractures and failed arthrodeses. JAMA
1982;247:623-8.

3. Borsalino G, Bagnacani M, Bettati E, Fornaciari F, Rocchi R, Uluhogian $\mathrm{S}$, et al. Electrical stimulation of human femoral intertrochanteric osteotomies. Double-blind study. Clin Orthop Relat Res 1988;(237):256-63.

4. Diniz P, Shomura K, Soejima K, Ito G. Effects of pulsed electromagnetic field (PEMF) stimulation on bone tissue like formation are dependent on the maturation stages of the osteoblasts. Bioelectromagnetics 2002;23:398-405.

5. Tsai MT, Chang WH, Chang K, Hou RJ, Wu TW. Pulsed electromagnetic fields affect osteoblast proliferation and differentiation in bone tissue engineering. Bioelectromagnetics 2007;28:519-28.

6. Selvamurugan N, Kwok S, Vasilov A, Jefcoat SC, Partridge NC. Effects of BMP-2 and pulsed electromagnetic field (PEMF) on rat primary osteoblastic cell proliferation and gene expression. $\mathrm{J}$ Orthop Res 2007;25:1213-20.

7. Farndale RW, Murray JC. Pulsed electromagnetic fields promote collagen production in bone marrow fibroblasts via athermal mechanisms. Calcif Tissue Int 1985;37:178-82.

8. Chang WH, Chen LT, Sun JS, Lin FH. Effect of pulse-burst electromagnetic field stimulation on osteoblast cell activities. Bioelectromagnetics 2004;25:457-65.

9. Greenough CG. The effects of pulsed electromagnetic fields on blood vessel growth in the rabbit ear chamber. J Orthop Res 1992; 10:256-62.

10. Roland D, Ferder M, Kothuru R, Faierman T, Strauch B. Effects of pulsed magnetic energy on a microsurgically transferred vessel. Plast Reconstr Surg 2000;105:1371-4.

11. Smith TL, Wong-Gibbons D, Maultsby J. Microcirculatory effects of pulsed electromagnetic fields. J Orthop Res 2004;22:80-4.

12. Sharrard WJ, Sutcliffe ML, Robson MJ, Maceachern AG. The treatment of fibrous non-union of fractures by pulsing electromagnetic stimulation. J Bone Joint Surg Br 1982;64:189-93.

13. Ito $H$, Shirai $Y$. The efficacy of ununited tibial fracture treatment using pulsing electromagnetic fields: relation to biological activity on nonunion bone ends. J Nihon Med Sch 2001;68:149-53.

14. Bose B. Outcomes after posterolateral lumbar fusion with instrumentation in patients treated with adjunctive pulsed electromagnetic field stimulation. Adv Ther 2001;18:12-20.

15. Linovitz RJ, Pathria M, Bernhardt M, Green D, Law MD, Mcguire RA, et al. Combined magnetic fields accelerate and increase spine fusion: a double-blind, randomized, placebo controlled study. Spine (Phila Pa 1976) 2002;27:1383-9.

16. Mackenzie D, Veninga FD. Reversal of delayed union of anterior cervical fusion treated with pulsed electromagnetic field stimulation: case report. South Med J 2004;97:519-24.

17. Varani K, Gessi S, Merighi S, Iannotta V, Cattabriga E, Spisani $\mathrm{S}$, et al. Effect of low frequency electromagnetic fields on A2A adenosine receptors in human neutrophils. Br J Pharmacol 2002; 136:57-66.

18. Sollazzo V, Traina GC, Demattei M, Pellati A, Pezzetti F, Caruso A. Responses of human MG-63 osteosarcoma cell line and human osteoblast-like cells to pulsed electromagnetic fields. Bioelectromagnetics 1997;18:541-7.

19. Reher P, Doan N, Bradnock B, Meghji S, Harris M. Effect of ultrasound on the production of IL-8, basic FGF and VEGF. Cytokine 1999;11:416-23.

20. Chang K, Chang WH, Tsai MT, Shih C. Pulsed electromagnetic fields accelerate apoptotic rate in osteoclasts. Connect Tissue Res 2006; 47:222-8

21. Chang K, Chang WH, Huang S, Huang S, Shih C. Pulsed electromagnetic fields stimulation affects osteoclast formation by modulation of osteoprotegerin, RANK ligand and macrophage colonystimulating factor. J Orthop Res 2005;23:1308-14.

22. Shimizu T, Zerwekh JE, Videman T, Gill K, Mooney V, Holmes $\mathrm{RE}$, et al. Bone ingrowth into porous calcium phosphate ceramics: influence of pulsing electromagnetic field. J Orthop Res 1988;6: 
248-58.

23. Spadaro JA, Albanese SA, Chase SE. Electromagnetic effects on bone formation at implants in the medullary canal in rabbits. $J$ Orthop Res 1990;8:685-93.

24. Ijiri K, Matsunaga S, Fukuyama K, Maeda S, Sakou T, Kitano M, et al. The effect of pulsing electromagnetic field on bone ingrowth into a porous coated implant. Anticancer Res 1996;16:2853-6.

25. Matsumoto H, Ochi M, Abiko Y, Hirose Y, Kaku T, Sakaguchi K. Pulsed electromagnetic fields promote bone formation around dental implants inserted into the femur of rabbits. Clin Oral Implants Res 2000;11:354-60.

26. Steinberg GG. Reversible osteolysis. J Arthroplasty 1995;10:5569.

27. Konrad K, Sevcic K, Foldes K, Piroska E, Molnar E. Therapy with pulsed electromagnetic fields in aseptic loosening of total hip protheses: a prospective study. Clin Rheumatol 1996;15:325-8.

28. Kennedy WF, Roberts CG, Zuege RC, Dicus WT. Use of pulsed electromagnetic fields in treatment of loosened cemented hip prostheses. A double-blind trial. Clin Orthop Relat Res 1993;(286): 198-205.

29. Claes L, Willie B. The enhancement of bone regeneration by ultrasound. Prog Biophys Mol Biol 2007;93:384-98.

30. Doan N, Reher P, Meghji S, Harris M. In vitro effects of therapeutic ultrasound on cell proliferation, protein synthesis, and cytokine production by human fibroblasts, osteoblasts, and monocytes. J Oral Maxillofac Surg 1999;57:409-19.

31. Takayama T, Suzuki N, Ikeda K, Shimada T, Suzuki A, Maeno $\mathrm{M}$, et al. Low-intensity pulsed ultrasound stimulates osteogenic differentiation in ROS 17/2.8 cells. Life Sci 2007;80:965-71.

32. Schumann D, Kujat R, Zellner J, Angele MK, Nerlich M, Mayr E, et al. Treatment of human mesenchymal stem cells with pulsed low intensity ultrasound enhances the chondrogenic phenotype in vitro. Biorheology 2006;43:431-43.

33. Duarte LR. The stimulation of bone growth by ultrasound. Arch Orthop Trauma Surg 1983;101:153-9.

34. Dyson M, Brookes M. Stimulation of bone repair by ultrasound. Ultrasound Med Biol 1983;Suppl 2:61-6.

35. Yang KH, Parvizi J, Wang SJ, Lewallen DG, Kinnick RR, Greenleaf JF, et al. Exposure to low-intensity ultrasound increases aggrecan gene expression in a rat femur fracture model. J Orthop Res 1996;14:802-9.

36. Rawool NM, Goldberg BB, Forsberg F, Winder AA, Hume E. Power Doppler assessment of vascular changes during fracture treatment with low-intensity ultrasound. J Ultrasound Med 2003; 22:145-53.

37. Eberson CP, Hogan KA, Moore DC, Ehrlich MG. Effect of lowintensity ultrasound stimulation on consolidation of the regenerate zone in a rat model of distraction osteogenesis. J Pediatr Orthop 2003;23:46-51.

38. Claes L, Ruter A, Mayr E. Low-intensity ultrasound enhances maturation of callus after segmental transport. Clin Orthop Relat Res 2005;(430):189-94.

39. Sakurakichi K, Tsuchiya H, Uehara K, Yamashiro T, Tomita K, Azuma Y. Effects of timing of low-intensity pulsed ultrasound on distraction osteogenesis. J Orthop Res 2004;22:395-403.

40. Chan CW, Qin L, Lee KM, Cheung WH, Cheng JC, Leung KS. Dose-dependent effect of low-intensity pulsed ultrasound on callus formation during rapid distraction osteogenesis. J Orthop Res 2006;24:2072-9.

41. ter Haar G. Therapeutic applications of ultrasound. Prog Biophys Mol Biol 2007;93:111-29.

42. Wang CJ, Chen HS, Chen CE, Yang KD. Treatment of nonunions of long bone fractures with shock waves. Clin Orthop Relat Res 2001;(387):95-101.

43. Heckman JD, Ryaby JP, McCabe J, Frey JJ, Kilcoyne RF. Acceleration of tibial fracture-healing by non-invasive, low-intensity pulsed ultrasound. J Bone Joint Surg Am 1994;76:26-34.
44. Welgus HG, Jeffrey JJ, Eisen AZ, Roswit WT, Stricklin GP. Human skin fibroblast collagenase: interaction with substrate and inhibitor. Coll Relat Res 1985;5:167-79.

45. Lin FH, Lin CC, Lu CM, Liu HC, Wang CY. The effects of ultrasonic stimulation on DP-bioglass bone substitute. Med Eng Phys 1995; 17:20-6.

46. Tanzer M, Harvey E, Kay A, Morton P, Bobyn JD. Effect of noninvasive low intensity ultrasound on bone growth into porous-coated implants. J Orthop Res 1996;14:901-6.

47. Tanzer M, Kantor S, Bobyn JD. Enhancement of bone growth into porous intramedullary implants using non-invasive low intensity ultrasound. J Orthop Res 2001;19:195-9.

48. Sutherland JC. Biological effects of polychromatic light. Photochem Photobiol 2002;76:164-70.

49. Karu TI, Kolyakov SF. Exact action spectra for cellular responses relevant to phototherapy. Photomed Laser Surg 2005;23:355-61.

50. Chen AC, Arany PR, Huang YY, Tomkinson EM, Sharma SK, Kharkwal GB, et al. Low-level laser therapy activates NF-kB via generation of reactive oxygen species in mouse embryonic fibroblasts. PLoS One 2011;6:e22453.

51. Moore P, Ridgway TD, Higbee RG, Howard EW, Lucroy MD. Effect of wavelength on low-intensity laser irradiation-stimulated cell proliferation in vitro. Lasers Surg Med 2005;36:8-12.

52. Hawkins D, Houreld N, Abrahamse H. Low level laser therapy (LLLT) as an effective therapeutic modality for delayed wound healing. Ann N Y Acad Sci 2005;1056:486-93.

53. Karu TI, Pyatibrat LV, Kalendo GS. Photobiological modulation of cell attachment via cytochrome c oxidase. Photochem Photobiol Sci 2004;3:211-6.

54. Bjordal JM, Klovning A, Lopes-Martins RA, Roland PD, Joensen J, Slordal L. Overviews and systematic reviews on low back pain. Ann Intern Med 2008;148:789-90.

55. Sobanko JF, Alster TS. Efficacy of low-level laser therapy for chronic cutaneous ulceration in humans: a review and discussion. Dermatol Surg 2008;34:991-1000.

56. Christie A, Jamtvedt G, Dahm KT, Moe RH, Haavardsholm EA, Hagen KB. Effectiveness of nonpharmacological and nonsurgical interventions for patients with rheumatoid arthritis: an overview of systematic reviews. Phys Ther 2007;87:1697-715.

57. Trimmer PA, Schwartz KM, Borland MK, De Taboada L, Streeter J, Oron U. Reduced axonal transport in Parkinson's disease cybrid neurites is restored by light therapy. Mol Neurodegener 2009;4:26.

58. Ad N, Oron U. Impact of low level laser irradiation on infarct size in the rat following myocardial infarction. Int $\mathrm{J}$ Cardiol 2001;80:109-16.

59. Anders JJ, Geuna S, Rochkind S. Phototherapy promotes regeneration and functional recovery of injured peripheral nerve. Neurol Res 2004;26:233-9.

60. Pyo SJ, Song WW, Kim IR, Park BS, Kim CH, Kim SS, et al. Effects of low level laser therapy (LLLT) on pressured human osteoblasts: a histomorphologic and quantitative study. Laser Physics 2012;22:620-5.

61. Chan AY, Bergman H. Performance verification of a prototype non-invasive intra-oral bone growth stimulator for titanium dental implants. Conf Proc IEEE Eng Med Biol Soc 2008;2008:5624-7.

62. Buzza EP, Shibli JA, Barbeiro RH, Barbosa JR. Effects of electromagnetic field on bone healing around commercially pure titanium surface: histologic and mechanical study in rabbits. Implant Dent 2003; 12:182-7.

63. Grana DR, Marcos HJ, Kokubu GA. Pulsed electromagnetic fields as adjuvant therapy in bone healing and peri-implant bone formation: an experimental study in rats. Acta Odontol Latinoam 2008:21:77-83.

64. Fini M, Cadossi R, Cane V, Cavani F, Giavaresi G, Krajewski A, et al. The effect of pulsed electromagnetic fields on the osteointegration of hydroxyapatite implants in cancellous bone: a morphologic and microstructural in vivo study. J Orthop Res 2002; 
20:756-63.

65. Denaro V, Cittadini A, Barnaba SA, Ruzzini L, Denaro L, Rettino A, et al. Static electromagnetic fields generated by corrosion currents inhibit human osteoblast differentiation. Spine (Phila Pa 1976) 2008;33:955-9.

66. Akca K, Sarac E, Baysal U, Fanuscu M, Chang TL, Cehreli M. Micro-morphologic changes around biophysically-stimulated titanium implants in ovariectomized rats. Head Face Med 2007;3:28.

67. Liu Q, Liu X, Liu B, Hu K, Zhou X, Ding Y. The effect of lowintensity pulsed ultrasound on the osseointegration of titanium dental implants. Br J Oral Maxillofac Surg 2012;50:244-50.

68. Shiraishi R, Masaki C, Toshinaga A, Okinaga T, Nishihara T, Yamanaka N, et al. The effects of low-intensity pulsed ultrasound exposure on gingival cells. J Periodontol 2011;82:1498-503.

69. Wijdicks CA, Virdi AS, Sena K, Sumner DR, Leven RM.
Ultrasound enhances recombinant human BMP-2 induced ectopic bone formation in a rat model. Ultrasound Med Biol 2009;35:162937.

70. Omasa S, Motoyoshi M, Arai Y, Ejima K, Shimizu N. Low-level laser therapy enhances the stability of orthodontic mini-implants via bone formation related to BMP-2 expression in a rat model. Photomed Laser Surg 2012;30:255-61.

71. Berbert FL, Sivieri-Araujo G, Ramalho LT, Pereira SA, Rodrigues DB, de Araujo MS. Quantification of fibrosis and mast cells in the tissue response of endodontic sealer irradiated by low-level laser therapy. Lasers Med Sci 2011;26:741-7.

72. Garcia-Morales JM, Tortamano-Neto P, Todescan FF, de Andrade JC Jr, Marotti J, Zezell DM. Stability of dental implants after irradiation with an 830-nm low-level laser: a double-blind randomized clinical study. Lasers Med Sci 2012;27:703-11. 